\title{
Das Primat der Politik in kaiserlicher Armee, Reichswehr, Wehrmacht und Bundeswehr
}

Rechtliche Sicherungen der Entscheidungsgewalt über Krieg und Frieden zwischen Politik und Militär

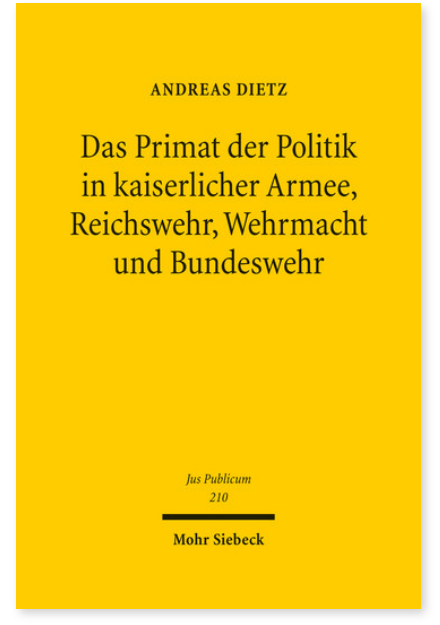

2011. XXVII, 780 Seiten. JusPubl 210

ISBN 978-3-16-151854-6

DOI 10.1628/978-3-16-151854-6

eBook PDF 159,00€

ISBN 978-3-16-150865-3

Leinen $159,00 €$
Nach Clausewitz ist das Militär nur ein Mittel der Politik. Die Stellung der Streitkräfte im Staat folgt daher dem Primat der Politik, in dem die zivile Führung die Entscheidungsgewalt über Krieg und Frieden hat. Dies zu sichern, ist Aufgabe einer Verfassung mittels Subordination des Militärs unter die zivile Exekutive, beider Legitimation durch das Parlament und seiner Integration in die Wertegemeinschaft. Defizite des Primats haben fatale Folgen, wie die Kriege Deutschlands bis heute zeigen. Andreas Dietz entwickelt die rechtlichen Vorgaben des Primats und misst an ihnen die Verfassungslage im Kaiserreich, in der Weimarer Republik, im »Dritten Reich«, in der Bundesrepublik und in der DDR. An den Auslandseinsätzen der Bundeswehr zeigt er aktuelle Defizite des Primats auf und fordert u. a. eine nationale Sicherheitsstrategie als Grundlage der Bundeswehrreform und künftiger Einsatzentscheidungen.

Andreas Dietz Geboren 1967; Studium der Rechtswissenschaften an der Universität Bayreuth; 2003 Promotion; seit 2006 Richter am Bayer. Verwaltungsgericht Augsburg und Lehrbeauftragter an der Juristischen Fakultät der Universität Augsburg; 2011 Habilitation.

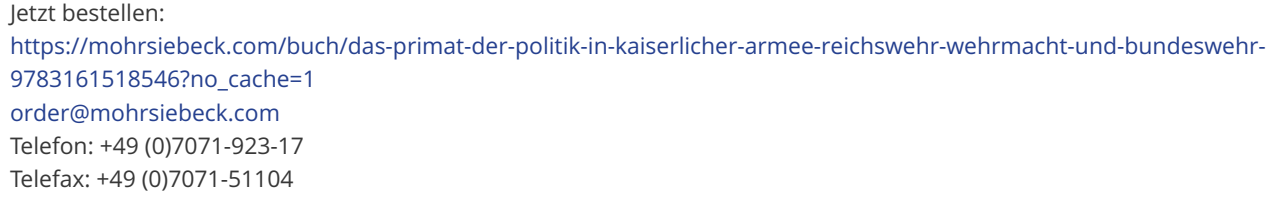

